\title{
Association between Diabetes Consequences and Quality of Life among Patients with Diabetes Mellitus in the Aseer Province of Saudi Arabia
}

Sultan M. Alshahrani ${ }^{1 *}$, Moferrah Alzahrani ${ }^{1}$, Khaled Alakhali ${ }^{1,2}$, Easwaran Vigneshwaran ${ }^{1}$, Mir Javid Iqbal ${ }^{1}$, Noohu Abdulla Khan $^{1}$, Abdullah Othman ${ }^{3}$, Yaser Al-Worafi' ${ }^{4}$, Sirajudeen S. Alavudeen ${ }^{1}$

${ }^{1}$ Department of Clinical Pharmacy, College of Pharmacy, King Khalid University, Abha-KSA; ${ }^{2}$ Department of Clinical Pharmacy, Faculty of Pharmaceutical sciences, UCSI University, Kuala Lumpur, Malaysia; ${ }^{3}$ Consultant Pediatric Endocrinologist and Director Aseer. Endocrine and Diabetes Centre, Aseer Central Hospital, Ministry of Health, Saudi Arabia; ${ }^{4}$ Department of Clinical Pharmacy, College of Pharmacy, University of Science and Technology of Fujairah, UAE

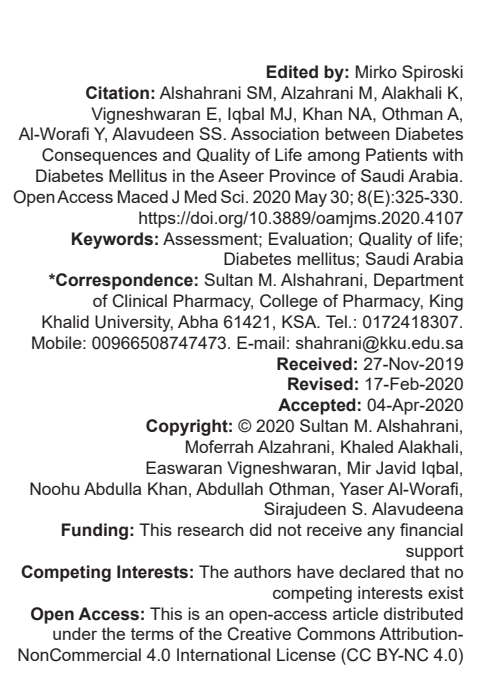

\section{Abstract}

BACKGROUND: Diabetes mellitus (DM) is a major health-care burden worldwide.

AIM: The aim of the study was to explore how the quality of life (QoL) of DM patients could be affected in the Aseer Province of the Kingdom of Saudi Arabia (KSA).

METHODS: A cross-sectional, multicenter study in DM patients of both sexes and all age groups in Aseer Province were done using a validated self-administered questionnaire. The study was conducted between April 1, 2018 and November 25, 2018.

RESULTS: A total of 418 patients completed our questionnaire, of which $240(58 \%)$ were male and $178(42 \%)$ were female. Furthermore, $50.23 \%$ were married and $104(24.16 \%)$ were illiterate. We found that $403(96.42 \%)$ respondents had type-2 DM and $315(75.35 \%)$ had a family history of DM. In addition, $132(31.57 \%)$ respondents were on monotherapy whereas only $61(14.59 \%)$ were using combination therapy. Hypertension was the most prevalent comorbidity $(166,39.71 \%)$ and peripheral neuropathy the most prevalent complication of DM $(157,37.56 \%)$.

CONCLUSION: DM had a significant impact on QoL among patients from Aseer Province in KSA. Our study underscores the importance of generating data on QoL among DM patients.

\section{Introduction}

Diabetes mellitus (DM) is a chronic disease that can affect quality of life (QoL) if the desired treatment outcomes are not achieved [1], [2]. Therefore, patients with DM should be counseled and educated about the impact of DM on their QoL, and encouraged to adhere to pharmacologic and non-pharmacologic management [3].

The prevalence of DM worldwide has been increasing worldwide and has been projected be $\sim 370$ million by 2030 [4]. There are two common types of DM, type 1 and type 2, and the latter represents $~ 90 \%$ of DM worldwide [5]. Over the past four decades, the Kingdom of Saudi Arabia (KSA) has witnessed major socioeconomic changes. As a result, the overall prevalence of DM among adults in KSA is 25\% [6].
QoL represents the ultimate goal of all health interventions [7]. It provides deep insight and information, irrespective of clinical data, on how the patient feels [8]. Evidence suggests that in DM, psychosocial factors play an important part in self-care, acceptance of therapeutic regimens, and treatment success and that metabolic measures (e.g., glycemic control) are poorly correlated with QoL [9]. DM complications have been found to have a negative effect on QoL [10]. Therefore, the main objective of DM treatment is to prevent DM complications and, therefore, improve the QoL of patients [1], [2]. An improvement in QoL not only benefits the patients but also reduces the social, financial, and psychological burden related to DM [1], [2].

The paucity of data related to QoL in the Aseer Province of KSA prompted us to evaluate the QoL of patients with DM and related complications. 


\section{Methods}

\section{Ethical approval of the study protocol}

The study protocol was approved from the Regional Ethical Committee of the Aseer Province (REC-2018-03-055). The purpose of the study was explained to respondents, and questions were administered only after seeking their consent for participation. The personal information of patients was not collected.

\section{Study design}

A cross-sectional study was conducted between April 1, 2018 and November 25, 2018. The study cohort was patients with type-1 and -2 DM in five primary care centers in the cities of Abha and Khamis Mushait in the Aseer Province in Southwest KSA.

\section{Sample size and sampling method}

The sample size ( $n$ ) was calculated based on the Cochran equation. The calculated sample size was 385. A convenient sampling method was used in this study. Patients with DM were invited to participate in this study.

\section{Study instrument and data collection}

A self-administered questionnaire was adapted from the literature [11]. This validated selfadministered questionnaire comprised 35 questions with four domains: Demographic and socioeconomic factors; clinical characteristics; QoL; and compliance of QoL.

Then, the study was carried out in a systematic and sequential manner. Step 1 involved development and validation of the questionnaire: $A$ focus group of academicians and DM consultants determined the domains affecting QoL. Step 2 comprised a pilot study conducted for validation. The World Health Organization Brief Quality of Life Questionnaire was used for comparison [11]. Step 3 was questionnaire administration; the questionnaire was administered in person during daily visits to health facilities in which the study was carried out.

\section{Statistical analysis}

Data were analyzed descriptively using SPSS v21 (IBM, Armonk, NY, USA). The Kruskal-Wallis test of significance $(p<0.05)$ was undertaken to assess the association between adherence and DM-specific QoL. A multiple regression analysis (backward-selection method) was used to identify the independent predictors of DM-specific QoL.

\section{Results}

\section{Patient demographics}

Out of 439 study participants, 417 (95.2\%) completed the questionnaire. Of these 417 participants, $240(58 \%)$ were male and $178(42 \%)$ were female. Most respondents were elderly $(159,38.08 \%)$. The lowest number of respondents $(21,5.02 \%)$ was $<20$ years of age. Furthermore, $210(50.23 \%)$ respondents were married. In addition, 55 (13.15\%) and $104(24.16 \%)$ respondents were illiterate, whereas $94(44.48 \%)$ had attained education at university level. Furthermore, 150 $(35.88 \%)$ were unemployed whereas $49(11.75 \%)$ were self-employed (Table 1).

\section{Patient distribution by clinical characteristics and treatment type}

Of the 418 people who completed the questionnaire, $403(96.42 \%)$ had type-2 DM and 315 $(75.35 \%)$ had a family history of DM. Furthermore, $148(35.40 \%)$ had an underlying chronic history of DM from 5 years, whereas $27(6.45 \%)$ were diagnosed recently (<1 year) with DM. In addition, $132(31.57 \%)$ respondents were on monotherapy whereas 61 $(14.59 \%)$ respondents were using combination therapy involving insulin. All patients had comorbidity, with hypertension being the most prevalent (166, 39.71\%), followed by asthma $(59,14.11 \%)$ and dyslipidemia $(58$, $13.88 \%)$. Peripheral neuropathy was the most common DM-induced complication (157, 37.56\%), followed by diabetic retinopathy $(93,22.25 \%)$ (Table 2$)$.

\section{Self-awareness of patients}

We found that 226 (54.07\%) respondents were well aware of hypoglycemic symptoms. Furthermore, $181(43.30 \%)$ respondents were physically inactive and

Table 1: Demographics of questionnaire respondents

\begin{tabular}{lll}
\hline Characteristic & Number & Percentage \\
\hline Sex & & \\
$\quad$ Male & 243 & 58 \\
Female & 174 & 42 \\
Age (years) & 21 & 5 \\
$<20$ & 56 & 13 \\
$20-39$ & 136 & 33 \\
$40-59$ & 157 & 38 \\
$60-79$ & 47 & 11 \\
$>80$ & & \\
Marital status & 207 & 50 \\
Unmarried & 56 & 13 \\
Married once & 70 & 17 \\
Married multiple times & 53 & 13 \\
Separated or divorced & 31 & 7 \\
Widowed & & \\
Education & 104 & 25 \\
None & 101 & 24 \\
Primary level & 118 & 28 \\
Secondary level & 94 & 23 \\
University & & \\
Work status & 78 & 19 \\
Government employee & 42 & 10 \\
Private employee & 69 & 17 \\
Self-employed & 49 & 43 \\
Unemployed & 179 & \\
Pensioner & &
\end{tabular}


108 (25.84\%) were carrying out physical activity for $<30$ min. In addition, 338 (88.85\%) of respondents did not know about their level of glycated hemoglobin, and $368(88.40 \%)$ were unaware of their body mass index. Worryingly, 163 (39.0\%) of respondents did not follow their dietician's advice and 332 (79.42) did not use or kept a necklace/bracelet saying that they had DM with them.

Table 2: Patient distribution by clinical characteristics and treatment type

\begin{tabular}{lll}
\hline Characteristic & Number & Percentage \\
\hline Type of DM & 399 & 96 \\
1 & 18 & 4 \\
2 & & \\
Family history of DM & 317 & 76 \\
$\quad$ Yes & 100 & 24 \\
$\quad$ No & & \\
How long you have been diagnosed with DM? & 27 & 6 \\
$\quad<1$ year & 147 & 35 \\
1-5 years & 118 & 28 \\
$5-10$ years & 125 & 30 \\
$>10$ years & & \\
Type of your therapeutic regimen & 132 & 32 \\
Monotherapy & 184 & 44 \\
Combination therapy including metformin & 40 & 10 \\
Combination therapy without metformin & 61 & 15 \\
$\quad$ Combination therapy including insulin & & \\
Comorbidity & 93 & 22 \\
$\quad$ None & 187 & 45 \\
One comorbidity & 93 & 22 \\
Two comorbidities & 44 & 11 \\
$\quad$ More than two comorbidities & & \\
DM complication & 64 & 15 \\
$\quad$ None & 80 & 19 \\
One complication & 188 & 45 \\
Two complications & 85 & 20 \\
$\quad$ More than two complications & & \\
\hline
\end{tabular}

DM: Diabetes mellitus.

We found that 372 (89\%) respondents were satisfied with their medications and that $90(22 \%)$ had an unpleasant experience with their existing drug therapy. Furthermore, 193 (46.45\%) respondents felt worrisome about the possible side effects of their drug therapy and $95(22.8 \%)$ used to skip their medications at times, with $194(46.6 \%)$ of them experiencing some side effects from their drugs. In addition, $52.6 \%$ of patients "felt isolated" for being served a different diet and $64.3 \%$

Table 3: Linear regression multivariable analysis for the relationship between demographic characteristics and overall QoL score

\begin{tabular}{llll}
\hline Variable & $\begin{array}{l}\text { Standardized } \\
\text { coefficient (beta) }\end{array}$ & $95 \% \mathrm{Cl}$ & p-value \\
\hline $\begin{array}{llll}\text { Sex } \\
\text { Male }\end{array}$ & Reference & Reference & Reference \\
Female & -0.251 & $-8.824--4.033$ & 0.000 \\
Age (years) & Reference & Reference & Reference \\
$<20$ & -0.048 & $-7.756-4.232$ & 0.564 \\
$20-39$ & -0.290 & $-13.311--2.326$ & 0.000 \\
$40-59$ & -0.509 & $-18.719--7.833$ & 0.005 \\
$60-79$ & -0.307 & $-18.418-6.121$ & 0.000 \\
$>80$ & & & \\
Marital status & Reference & Reference & Reference \\
Unmarried & 0.145 & $1.704-9.031$ & 0.004 \\
Married once & -0.010 & $-3.726-3.035$ & 0.841 \\
Married multiple times & -0.153 & $-9.540--2.051$ & 0.002 \\
Separated/divorced & -0.050 & $-7.103-2.267$ & 0.311 \\
Widowed & & & \\
Education & Reference & Reference & Reference \\
None & 0.098 & -0.349 to 6.143 & 0.080 \\
Primary level & 0.264 & 4.278 to 10.529 & 0.000 \\
Secondary Level & 0.416 & 9.292 to 15.90 & 0.000 \\
University & & & \\
Work status & 0.252 & $3.91-12.44$ & 0.000 \\
Government employee & 0.055 & $-2.63-7.284$ & 0.358 \\
Private employee & -0.106 & $-7.99-0.754$ & 0.105 \\
Self-employed & Reference & Reference & Reference \\
Unemployed & -0.103 & $-6.40-1.120$ & 0.168 \\
Pensioner & & & \\
\hline QoL: Quality of life, Cl: Confidence interval. & & \\
& & & \\
& & &
\end{tabular}

"hated being watched for that they ate." Furthermore, $77.9 \%$ "felt bad for not being able to eat what they like." More than $50 \%$ of respondents felt depressed because of the underlying disease and $91.1 \%$ worried about their children getting affected with the same disease (Tables 3 and 4).

\section{Patient-related QoL}

More than $70.0 \%$ of respondents stated that DM affected their general health and routine activities, such as working, shopping, and travelling. However, $23.4 \%$ of respondents stated that DM did not affect their capacity to work. Furthermore, 12\% of respondents were undecided if DM affected their work capacity, whereas $66.26 \%$ felt strongly that absence from work was because of DM. More than $50 \%$ of respondents attributed their disassociation from family/social occasions to DM. In addition, $60.0 \%$ of Table 4: Linear regression multivariable analysis of the relationship between clinical characteristics and overall QoL score

\begin{tabular}{|c|c|c|c|}
\hline Variable & $\begin{array}{l}\text { Standardized } \\
\text { coefficient (beta) }\end{array}$ & $95 \% \mathrm{Cl}$ & p-value \\
\hline \multicolumn{4}{|l|}{ Type of DM } \\
\hline 1 & Reference & Reference & Reference \\
\hline 2 & 0.094 & $-0.145-12.142$ & 0.056 \\
\hline \multicolumn{4}{|l|}{ Family history of DM } \\
\hline Yes & Reference & Reference & Reference \\
\hline No & 0.234 & $4.146-9.704$ & 0.000 \\
\hline \multicolumn{4}{|c|}{ How long you have been diagnosed with DM? } \\
\hline$<1$ year & 0.040 & $-3.134-7.253$ & 0.436 \\
\hline $1-5$ years & 0.233 & $3.197-9.152$ & 0.000 \\
\hline $5-10$ years & 0.083 & $-0.824--5.458$ & 0.148 \\
\hline$>10$ years & Reference & Reference & Reference \\
\hline \multicolumn{4}{|l|}{ Therapeutic regimen } \\
\hline Monotherapy & Reference & Reference & Reference \\
\hline $\begin{array}{l}\text { Combination therapy including } \\
\text { metformin }\end{array}$ & -0.31 & $-8.606--3.154$ & 0.000 \\
\hline $\begin{array}{l}\text { Combination therapy without } \\
\text { metformin }\end{array}$ & 0.028 & $-3.127-5.50$ & 0.584 \\
\hline $\begin{array}{l}\text { Combination therapy including } \\
\text { insulin }\end{array}$ & -0.102 & $-0.060-7.341$ & 0.054 \\
\hline \multicolumn{4}{|l|}{ Comorbidity } \\
\hline None & 0.231 & $2.56-11.46$ & 0.002 \\
\hline One comorbidity & 0.25 & $-3.44-4.70$ & 0.762 \\
\hline Two comorbidities & -0.27 & $-5.25-3.63$ & 0.720 \\
\hline $\begin{array}{l}\text { Three or more than three } \\
\text { comorbidities }\end{array}$ & Reference & Reference & Reference \\
\hline \multicolumn{4}{|l|}{ DM complications } \\
\hline None & 0.455 & 12.207-19.702 & 0.000 \\
\hline One complication & 0.089 & $-0.648-6.469$ & 0.109 \\
\hline Two compilations & 0.117 & $-0.036-5.925$ & 0.047 \\
\hline Three complications & Reference & Reference & Reference \\
\hline
\end{tabular}

respondents stated that their disease had an impact on routine activities such as long talks, conversations, prayers, sleeping, and travelling on long road trips, and $29.2 \%$ stated that DM did not affect their relationship with friends/wife/children/coworkers. However, $50 \%$ of respondents were undecided on whether DM affected their sexual health, and $50 \%$ of respondents felt that DM affected their sexual health (Table 5).

Table 5: Mean QoL scores in various domains

\begin{tabular}{ll}
\hline Domain & Mean \pm SD \\
\hline Patient's self-awareness of DM & $38.63 \pm 18.43$ \\
Patient's experience of drugs and DM & $35.25 \pm 14.447$ \\
Patient-related QoL & $49.57 \pm 25.69$ \\
Overall QoL & $41.17 \pm 12.662$ \\
\hline
\end{tabular}




\section{Discussion}

QoL evaluation is a fundamental component when providing healthcare in patients with $\mathrm{DM}$. In recent years, there has been growing appreciation of the patient's perspective on health, disease, and medical treatments. DM prevalence in KSA is underestimated. Only a few national/regional DM registries are available to support DM research and provide reliable data on various aspects of the disease [11]. We investigated QoL among patients with DM, with a focus on the clinical, mental and psychosocial factors that affect QoL.

Most respondents were elderly, married, and illiterate. A sex-specific significant difference in QoL was not found among study participants. These results are in accordance with data from Brown et al., who reported that neither sex, education level nor age affected QoL significantly [12]. However, in western countries, lower QoL in women suffering from DM was reported by Rubin and Peyrot in 2004 [3]. Similar results have been reported by Redekop et al. and Aghamollaei et al. in 2002 and 2003, respectively [13], [14], [15].

We found that $96.42 \%$ of respondents had type-2 DM, with $75.35 \%$ having a family history of DM. Most respondents had an underlying chronic history of DM. Family history was found to be a stressful factor and reduced their QoL because they felt that their children were equally susceptible to the disease. Hypertension and asthma were common comorbidities, whereas peripheral neuropathy and retinopathy were common complications of DM. Moreover, respondents with neuropathic pain experienced a reduction in sleep, walking, and ability to undertake domestic duties. DM impairs all dimensions of health [11], [15]. Brown et al. reported that the type and duration of DM had an impact on QoL. DM complications, such as retinopathy and peripheral sensory neuropathy, have been associated with poor QoL in several studies, and painful diabetic neuropathy has a significant impact on QoL [16], [17].

Satisfaction with use of medications has a key role in terms of treatment compliance. Several studies have reported that long-term maintenance of drug therapy and glycemic control is dependent on adherence to medication and lifestyle changes. Most respondents $(89 \%)$ were satisfied with the medications they were taking [18]. However, factors such as unpleasant taste and the side effects of medications had an impact on medication adherence among study respondents. More than $50 \%$ of respondents felt depressed because of their underlying disease and were worried about their children getting affected by DM. The results of our study are in accordance with those of Farias et al. [19]. They suggested that the QoL of patients with DM may influence treatment adherence, improve clinical outcomes satisfactorily, and reduce the prevalence of morbidity and mortality and disease progression. The relationship between QoL and treatment adherence remains controversial. Some scholars have shown the highest QoL level in patients with DM to be associated with better treatment adherence, whereas other researchers have not identified this association [19], [20].

Self-awareness and management of the complications and symptoms of DM have been positively correlated with QoL [21]. Self-management activities demand require effort, which many people find difficult to incorporate into their daily life [22], [23]. More than $50 \%$ of respondents were found to be self-aware about symptom management but these respondents were also found to be physically inactive. These results are in accordance with other studies that have reported that the duration of DM is associated with the level of DM knowledge [24]. Yun et al. and Kamel et al. observed a linear relationship between overall knowledge of DM and DM management. However, in another study, it was reported that people with DM lacked knowledge and, consequently, had low levels of self-care practices [25], [26]. Another study reported that exercise was associated with improved QoL among people with DM [27].

DM affects the QoL of the patient and his/ her family due to its chronic nature, and its severity has been found to be associated with lower QoL [21]. Social isolation and dietary restriction had a negative impact on QoL among study respondents: $>50 \%$ of respondents felt isolated for being served a different diet to that of other people. Moreover, monitoring what DM patients eat was found to have a negative impact on their QoL in the present study. Seventy-percent of respondents faced difficulties in routine activities, such as working, shopping, travelling, and praying.

\section{Conclusion}

DM had a significant impact on QoL among patients from the Aseer Province of KSA. Moreover, DM patients should be involved in awareness and counseling sessions to gain more knowledge regarding DM and its consequences. Our study underscores the importance of generating more data on QoL among DM patients.

\section{Authors' Contributions}

SMA and MJA conceived the study. AO, $\mathrm{NAK}$, and $\mathrm{YAH}$ were involved in domain selection and questionnaire validation. MA, SSA, EV, and KA helped in data collection and statistical analyses. All authors participated in writing or reviewing the manuscript. 

of interest.

All authors declare that there are no conflicts

\section{Acknowledgments}

We are thankful to the Dean of King Khalid University and the Director of the Aseer Diabetic Center, whose contribution made the study possible.

\section{References}

1 American Diabetes Association. Classification and diagnosis of diabetes: Standards of medical care in diabetes 2019. Diabetes Care. 2019;42(Suppl 1):S13-28. https://doi.org/10.2337/ dc19-s002

2 Colberg SR, Albright AL, Blissmer BJ, Rubin RR, ChasanTaber L, Albright AL, et al. Exercise and Type 2 diabetes: American college of sports medicine and the American Diabetes Association: Joint position statement. Med Sci Sports Exerc. 2010;42(12):2282-303. https://doi.org/10.1249/ mss.0b013e3181eeb61c

3 Wild S, Roglic G, Green A, Sicree R, King H. Global prevalence of diabetes: Estimates for the year 2000 and projections for 2030. Diabetes Care. 2004;27(5):1047-53. https://doi. org/10.2337/diacare.27.5.1047

\section{PMid:15111519}

4 World Health Organization. Ten Facts on Diabetes. Available from: http://www.who.int/features/factfiles/diabetes/en. [Last accessed on 2018 Apr 08].

5 Al-Nozha M, Al-Maatouq M, Al-Mazrou Y, Al-Harthi SS, Arafah MR, Khalil MZ, et al. Diabetes mellitus in Saudi Arabia. Saudi Med J. 2004;25(11):1603-10. https://doi.org/10.1016/j. jsha.2009.06.007

PMid: 15573186

6 Rubin RR, Peyrot M. Quality of life and diabetes. Diabetes Metab Res Rev. 1999;15(3):20518.

PMid: 10441043

7 Pera PI. Living with diabetes: Quality of care and quality of life. Patient Prefer Adherence. 2011;5:65-72.

PMid:21423590

8 Nagpal J, Kumar A, Kakar S, Bhartia A. The development of quality of life instrument for Indian diabetes patients (QOLID): A validation and reliability study in middle and higher income groups. J Assoc Physicians India. 2010;58:295-304.

\section{PMid:21117348}

9 Kasyap JV, Niveditha G, Harsha KP, Kumar P. Evaluation of targets achieved, quality of care and life in Type 2 diabetes mellitus patients in a tertiary care hospital. Res Rev J Med Health Sci. 2013;2(3):94100.

10 World Health Organization. WHOQOL-BREF. Introduction, Administration and Scoring and Generic Version of the Assessment. Field Trial version. Geneva: World Health Organization; 1996.

11 Al-Shehri FS. Quality of life among Saudi diabetics. J Diabetes Mellitus. 2014;4:225-31. https://doi.org/10.4236/ jdm.2014.43032
12 Brown GC, Brown MM, Sharma S, Brown H, Gozum M, Denton P. Quality of life associated with diabetes mellitus in an adult population. J Diabetes Comp. 2000;14(1):18-24.

PMid:10925062

13 Rubin RR, Peyrot M. Quality of life and diabetes. Diabetes Metab Res Rev. 2004;15(3):205-18

PMid:10441043

14 Redekop, WK, Koopmanschap MA, Stolk RP, Rutten GE, Wolffenbuttel $\mathrm{BH}$, et al. Health-related quality of life and treatment satisfaction in Dutch patients with Type 2 diabetes. Diabetes Care. 2002;25(3):458-63. https://doi.org/10.2337/ diacare.25.3.458

PMid: 11874930

15 Aghamollaei T, Eftekhar H, Shojaeizadeh D, Mohammad K, Nakhjavani M, Pour FG. Behavior, metabolic control and healthrelated quality of life in diabetic patients at Bandar Abbas Diabetic Clinic. Iran J Pub Health 2003;32:54-9.

16 Benbow SJ, Wallymahmed ME, MacFarlane IA. Diabetic peripheral neuropathy and quality of life. QJM. 1998;91:733-7. https://doi.org/10.1093/qjmed/91.11.733

17 Goldney RD, Philips PJ, Fisher LJ, Wilson DH Diabetes, depression, and quality of life. Diabetes Care. 2004;27:1066-70. https://doi.org/10.2337/diacare.27.5.1066

18 Tennvalla GR, Apelqvistb J. Health-related quality of life in patients with diabetes mellitus and foot ulcers. J Diabetes Comp. 2000;14(5):235-41. https://doi.org/10.1016/ s1056-8727(00)00133-1

PMid:11113684

19 Farias MS, Agra CC, Araújo LK, Correia DS, Cavalcante JC Treatment adherence and life quality of diabetic patients assisted in the primary care division. Rev Soc Bras Clín Med. 2014;12(2):102-7.

20 O'Neil KJ, Jonnalagadda SS, Hopkins BL, Kicklighter JR. Quality of life and diabetes knowledge of young persons with Type 1 diabetes: Influence of treatment modalities and demographics. J Am Diet Assoc. 2005;105(1):85-91. https://doi.org/10.1016/j. jada.2004.10.010 PMid:15635351

21 Alfian SD, Sukandar H, Lestari K, Abdulah R. Medication adherence contributes to an improved quality of life in Type 2 diabetes mellitus patients: A cross-sectional study. Diabetes Ther. 2016;7(4):755-64. https://doi.org/10.1007/ s13300-016-0203-x

PMid:27718218

22 Kueh YC, Morris T, Borkoles E, Shee H. Modelling of diabetes knowledge, attitudes, self management, and quality of life: A cross-sectional study with an Australian sample. Health Qual Life Outcomes. 2015;13:129. https://doi.org/10.1186/ s12955-015-0303-8

PMid:26286395

23 Chawla K, Kalra S, Kalra B. Role of psychology in diabetes management. J Endocrinol 2009;6:1

24 Glasgow RE, Eakin EG. Issues in diabetes self-management. In: Shumaker SA, Schron EB, Ockene JK, McBee WL, editors. Handbook of Health Behavior Change. New York: Springer; 1998. p. 435-61.

25 Yun LS, Hassan Y, Aziz NA, Awaisu A, Ghazali R. A comparison of knowledge of diabetes mellitus between patients with diabetes and healthy adults: A survey from North Malaysia. Patient Educ Couns. 2007;69(1-3):47-54. https://doi.org/10.1016/j. pec.2007.06.017

PMid:17720351

26 Kamel NM, Badawy YA, El-Zeiny NA, Merdan IA Sociodemographic determinants of management behaviour of diabetic patient's part II. Diabetics' knowledge of the disease 
and their management behavior. East Mediterr Health J. 1999;5(5):974-83.

PMid:10983537

27 Smith DW, McFall SL. The relationship of diet and exercise for weight control and the quality of life gap associated with diabetes. J Psychosom Res. 2005;59(6):385-92. https://doi. org/10.1016/j.jpsychores.2005.06.062

PMid:16310020 